\title{
WEAR CHARACTERISTICS OF SLURRY PUMP PARTS AT SHIELD TUNNELING WORK
}

\author{
By Tatsuro MURO* and Ryoichi FUKAGAWA**
}

\begin{abstract}
Long life and reliability in pumping abrasive slurry are more important than initial cost and efficiency. Here, several wear tests for impeller, reducer and frontliner of unshrouded centrifugal pump were executed at 2 sites of shield tunneling work. The influences of soil and metal including some surface coatings properties on the wear characteristics of pump parts were investigated. As the results, the effects of surface coatings treated on a reducer are displayed remarkably at initial stage of wear. To prevent the eccentric wear at a bottom of reducer or frontliner, it is necessary to increase the flow velocity at the inlet of pump not to occur a state of bed-load slurry movement, or to rotate their setting positions periodically.
\end{abstract}

\section{INTRODUCTION}

In recent years, a pressurized slurry shield tunneling work was executed for cutting a sandy ground mixed with gravel. So far, several studies ${ }^{1.2)}$ on the wear resistance of elastic high molecule compounds used for linings in the straight or bend slurry pipelines were carried out. For wear of slurry pump parts, only a few reports of field test ${ }^{3)}$ on the wear lives of specialized and normal cast iron of dredger pump can be found. It is very important problems for conducting a smooth work, that the wear amount of pump parts transporting heavy slurry sand mixed with gravel is remarkably larger than that of pipelines and there are many accidents due to short life of pump parts. Therefore, it is significant for decreasing the machinery cost to establish a supply system of pump parts by means of estimating accurately their wear lives and to elongate their lives due to improvement of their materials or of design method of slurry pump system. To analyse the wear characteristics of pump parts, it is necessary to clarify the soil and metal properties, and the hydrodynamic phenomena of slurry in the pump. Here, the wear amount and shape variation of representative slurry pump parts, i. e. impeller, reducer and frontliner were measured at 2 sites of shield tunneling work. Then, the wear characteristics of each pump part was clarified, and the influences of properties of soil and metal including some surface coatings on their wear characteristics were considered.

\section{SLURRY TRANSPORTATION SYSTEM}

Fig. 1 shows the slurry transportation system for the shield tunneling sites I and II. The tunnel dimensions, ground properties and feed and drainage slurry pump equipments are shown in Table $1 . \mathrm{P}_{2}$ pump set up just behind the pit face or the slurry crusher is a speed adjustable pump which varies from 350

* Member of JSCE Dr. Eng., Professor, Department of Ocean Engineering, Ehime University (Bunkyo 3 Matsuyama)

** Member of JSCE M. Eng., Assistant, Department of Civil Engineering, Kyoto University (Yoshida Honmachi, Sakyo-Ku, Kyoto) 


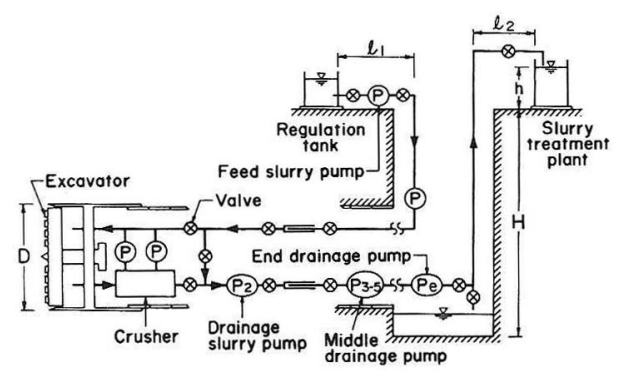

Fig. 1 Slurry transportation system.

to 1050 r. p. m. in accordance with load. The end drainage slurry pump $\mathrm{P}_{e}$ can be selected to operate at 885 or 1185 r. p. m. to keep balance in the transportation system. The middle drainage pump $P_{3 \sim 5}$ is always operated at constant speed 1185 r. p. m. . The total distance of drainage pipelines is $1179 \mathrm{~m}$ horizontal and $30 \mathrm{~m}$ vertical in site $\mathrm{I}$, and $966 \mathrm{~m}$ horizontal and $18 \mathrm{~m}$ vertical insite II . As in site I large stones were often excavated, a single toggle crusher breaking up in water was set between the shield excavator and $\mathrm{P}_{2}$ pump. The inlet size is $250 \times 500 \mathrm{~mm}$, the outlet one is (30 to 50$) \times$ $500 \mathrm{~mm}$, and its crushing capacity is greater than $166.6 \mathrm{kN} / \mathrm{h}$. And, 2 circulation pumps were set up between the shield excavator, feed and drainag slurry pipelines. The pressure of slurry at pit face ${ }^{4)}$ to stabilize the cutting wall was controlled to be 98 to $176 \mathrm{kPa}$. This pressure was large enough not to cause a cavitation at $\mathrm{P}_{2}$ pump, even if the hydraulic head loss in crusher was calculated. Total head and axial power of each pump were designed and controlled not to cause a cavitation at the rear pump.

Photo. 1 shows a full view of $\mathrm{P}_{2}$ pump. Fig. 2 shows the deal drawing of unshrouded centrifugal slurry pump and the initial dimensions of each pump part. The heavy solid lines show th parts of surface coating due to thermal spray. Several impellers having 2 or 4 blades and 390, 440 and $580 \mathrm{~mm}$ diameter were used in accordance with load. The wear tests have been done for impeller, reducer and frontliner. In the period of wear test, the positions of reducer and frontliner were set on the same situation as before after each shape variation due to wear and wear amount had been measured.

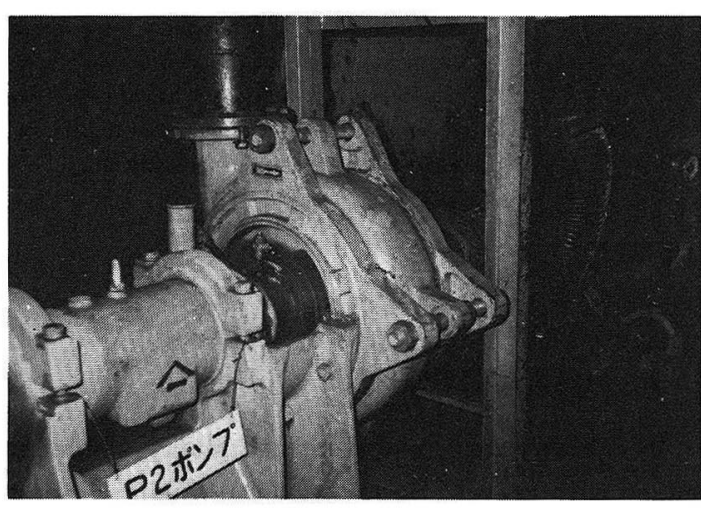

Photo. 1 Slurry pump $\mathrm{P}_{2}$.

Table 1 Tunnel dimensions, feed and drainage slurry pump equipments.

\begin{tabular}{|c|c|c|c|c|c|c|c|}
\hline \multicolumn{2}{|r|}{ Site } & \multicolumn{3}{|c|}{ I } & \multicolumn{3}{|c|}{ II } \\
\hline \multicolumn{2}{|c|}{ Outer diameter of shield $\mathrm{D}(\mathrm{mm})$} & \multicolumn{3}{|c|}{4300} & \multicolumn{3}{|c|}{3550} \\
\hline \multirow{2}{*}{\multicolumn{2}{|c|}{$\begin{array}{l}\text { Max. excavation distance } \\
\text { Depth of shaft }\end{array}$}} & \multirow{2}{*}{\multicolumn{3}{|c|}{$\frac{1029}{25}$}} & \multirow{2}{*}{\multicolumn{3}{|c|}{$\frac{779}{11}$}} \\
\hline & & & & & & & \\
\hline \multicolumn{2}{|c|}{$\begin{array}{l}\text { Distance between shaft and } l_{1}(\mathrm{~m}) \\
\text { regulation tank }\end{array}$} & \multicolumn{3}{|c|}{30} & \multicolumn{3}{|c|}{20} \\
\hline \multicolumn{2}{|c|}{$\begin{array}{l}\text { Distance between shaft and } l_{2}(\mathrm{~m}) \\
\text { slurry treatment plant }\end{array}$} & \multicolumn{3}{|c|}{30} & \multicolumn{3}{|c|}{20} \\
\hline \multicolumn{2}{|c|}{ 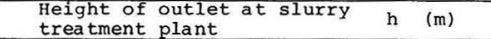 } & \multicolumn{3}{|c|}{5} & \multicolumn{3}{|c|}{10} \\
\hline \multicolumn{2}{|c|}{ Excavation speed $\quad(\mathrm{cm} / \mathrm{min})$} & \multicolumn{3}{|c|}{3} & \multicolumn{3}{|c|}{1.24} \\
\hline \multirow{2}{*}{ Ground } & Specific gravity & \multicolumn{3}{|c|}{2.700} & \multirow{2}{*}{\multicolumn{3}{|c|}{2.676}} \\
\hline & Water content & \multirow{2}{*}{\multicolumn{3}{|c|}{$\frac{15.0}{12.74}$}} & & & \\
\hline \multirow{2}{*}{$\begin{array}{l}\text { Specific gravity } \\
\text { of liquid }\end{array}$} & Feed slurry $\left(\mathrm{kN} / \mathrm{m}^{3}\right)$ & & & & \multicolumn{3}{|c|}{11.76} \\
\hline & Drainage slurry $\left(\mathrm{kN} / \mathrm{m}^{3}\right)$ & \multicolumn{3}{|c|}{13.62} & \multicolumn{3}{|c|}{12.05} \\
\hline \multirow{3}{*}{ Concentration } & Feed slurry & & 17.6 & & & 11.8 & \\
\hline & \begin{tabular}{|l|l|}
\cline { 2 - 2 } & Wt. $(\%)$ \\
\end{tabular} & & $\frac{36.7}{23.0}$ & & & $\frac{29.1}{13.5}$ & \\
\hline & Drainage slurry & & 44.6 & & & 29.6 & \\
\hline Flow rate & Feed slurry $\quad\left(\mathrm{m}^{3} / \mathrm{min}\right)$ & & 3.86 & & & 3.34 & \\
\hline Flow rate & Drainage slurry $\left(\mathrm{m}^{3} / \mathrm{min}\right)$ & & 4.30 & & & 3.50 & \\
\hline Inner diameter & Feed slurry $\quad(\mathrm{mm})$ & & 204.7 & & & 204. & \\
\hline of straight pipe & Drainage slurry & & 155.2 & & & 155. & \\
\hline Velocity of flow & Feed slurry & & 1.95 & & & 1.69 & \\
\hline velodity OI IIOW & Drainage slurry & & 3.79 & & & 3.09 & \\
\hline $\begin{array}{l}\text { Characteristic } \\
\text { slurry pump }\end{array}$ & cs of feed and drainage & $P_{2}$ & $P_{3 \sim 5}$ & $\mathrm{Pe}$ & $\mathrm{P}_{2}$ & $P_{3} \sim 5$ & $\mathrm{P}_{\mathrm{e}}$ \\
\hline Head & (m) & 27 & 34.5 & $34.5 / 17.5$ & 31 & 22.5 & 22.5 \\
\hline Rotation spee & (r.p.m.) & 1050 & 1185 & $1185 / 885$ & 1050 & 1185 & $1185 / 885$ \\
\hline Slurry effici & iency & 50.3 & 48.6 & $48.6 / 55.7$ & 50.3 & 48.6 & $48.6 / 55.7$ \\
\hline Axial power & $(\mathrm{Kw})$ & 52.4 & 69.2 & $69.2 / 33.9$ & 43.60 & 32.75 & $32.75 / 28.58$ \\
\hline Range of rota & ation speed & $\begin{array}{l}1050 \\
\sim 350\end{array}$ & 1185 & $1185 / 885$ & $\begin{array}{l}1050 \\
\sim 350\end{array}$ & 1185 & $1185 / 885$ \\
\hline Output of pow & $(\mathrm{Kw})$ & 75 & 75 & 75 & 75 & 75 & 75 \\
\hline
\end{tabular}




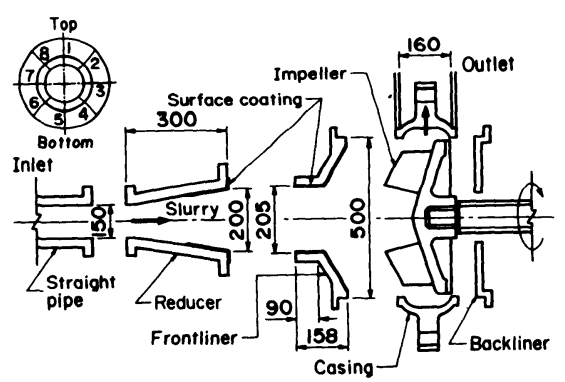

Fig. 2 Deal drawing of slurry pump.

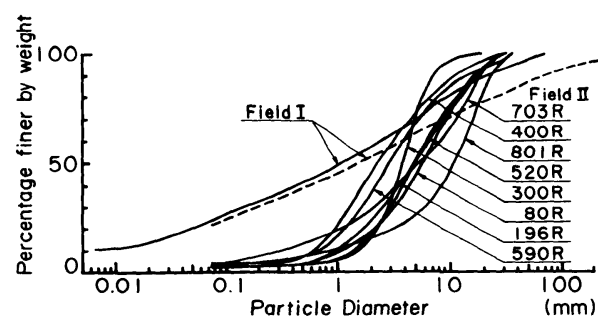

Fig. 3 Grain-size distribution of slurry.

\section{(1) Slurry properties}

Fig. 3 shows the grain-size distributions of slurry soil sampled from sites I and II. The broken line means that of original soil sampled from site $\mathrm{I}$. The original grain-size distribution which is composed of $45 \%$ gravel, $32 \%$ sand, $15 \%$ silt, $8 \%$ clay and $250 \mathrm{~mm}$ maximum grain size varies to the one which is composed of $58 \mathrm{~mm}$ maximum grain size, $1 \mathrm{~mm}$ average grain size, and 343 coefficient of uniformity after passing the slurry crusher. The average modified index of roundness of crushed particles is 0.38 , and the shape is fairly angular. The mineral compositions of stone sampled in this site cosist of $19 \%$ quartz, $16 \%$ feldspar, $6 \%$ detritus and $59 \%$ groundmass. The original soil sampled from site II is fairly uniform quartz sand of which maximum grain size is 20 to $40 \mathrm{~mm}$, average grain size is 2 to $10 \mathrm{~mm}$, and coefficient of uniformity is 2.9 to 7.6 from those grain size analyses at each about 100 rings $(1 \mathrm{ring}=90 \mathrm{~cm})$. The average modified index of roundness is 0.40 and the shape is slightly angular. The mineral compositions of stone cosist of $28 \%$ quartz, $39 \%$ plagioclase, $28 \%$ potassium feldspar, $6 \%$ detritus and $83 \%$ groundmass.

The limit deposit velocities of slurry in th straight drainage pipe of sites I and II are calculated to be 3.23 and $3.05 \mathrm{~m} / \mathrm{s}$ respectively by means of Durand's experimental equation ${ }^{5)}$. As the designed flow velocities exceed those limit deposit velocities in either case, the slurry particles are in the state of suspended flow and the amount of wear of straight pipe is comparatively small. And the slurry flows in those pipes are in the state of turbulent flow, as the Reynold's number of slurry of sites I and II are calculated to be $8.18 \times 10^{5}$ and $5.90 \times 10^{5}$ respectively. Ogawa ${ }^{6}$ suggested that the diameter of straight pipe should be designed to be as large as possible on the limit of suspended flow in order to decrease the wear amount of drainage straight pipe. He defined that the wear amount was the weight loss of metal per unit length of pipe and unit weight of soil trasported. The condition was satisfied enough in this slurry transportation system.

\section{(2) Metal properties}

The parent metal of casing, impeller and backliner was $20 \mathrm{Cr}$ cast iron. For the parent metal of frontliner, $20 \mathrm{Cr}$ and $27 \mathrm{Cr}$ cast iron were used. And for the parent metal of reduce carbon steel and $20 \mathrm{Cr}$ cast iron were used.

At the site $I$, the wear tests of impeller and frontliner were executed for their non-treated parent metals. At the site II, the wear tests of reducer and frontliner were executed for both their non-treated parent metals and surface coated parent metals by powder spray.

Table 2 shows the chemical compositions and mechanical properties of parent metal of pump parts and surface coatings. The surface hardness of parent metal $A, B$ and $C$ were measured on the worn surface of pump parts respectively.

Metal A is a $20 \mathrm{Cr}$ cast iron. Metal A(1), A (2) and A (3) are the parent metal of casing, impeller and backliner used in the site $I$, respectively. As the casing having a complicated shape and various thickness was cooled gradually or released a residual stress after heating, the surface and center hardness attained 
Table 2 Metal properties of pump parts and surface coatings.

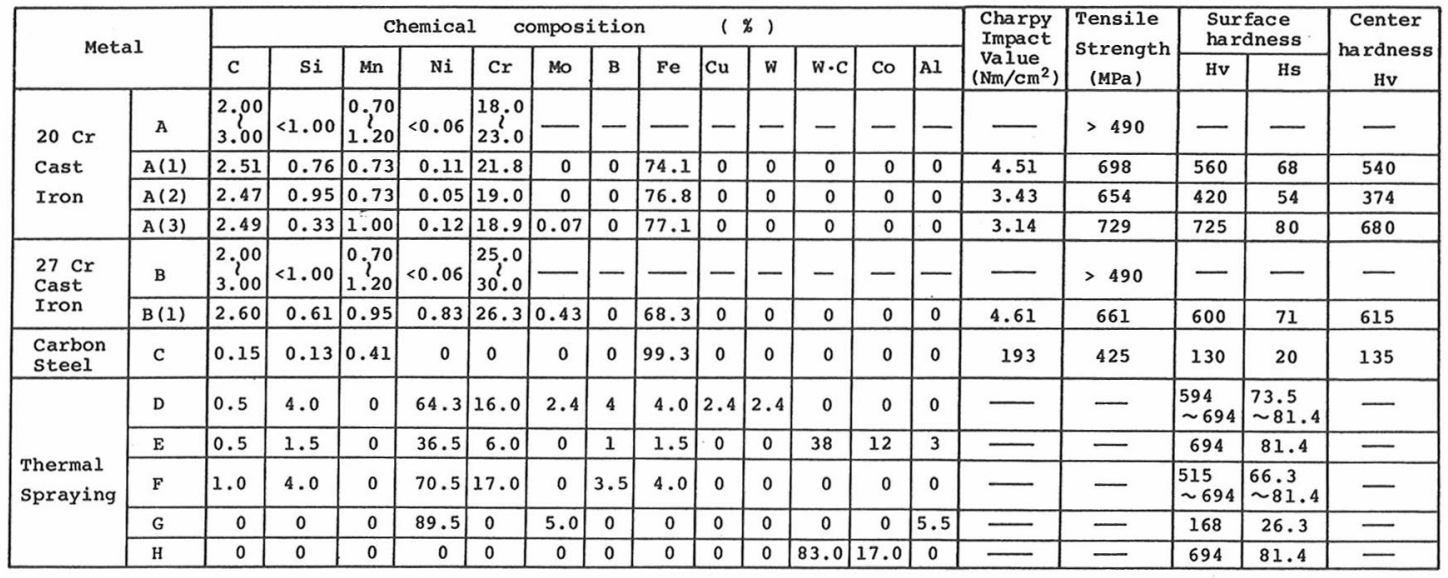

to a middle value among them. The hardness of impeller attained to a lower value because it was annealed in order to make a screw. The backliner having a comparatively simple shape got a higher surface hardness due to quenching. But the center hardness decreased slightly due to a small quantity of chemical element such as molybdenum that displayed a quenching effect. Photo.2(a), (b), (c) show the microscopic photographs of metallic texture of metal $\mathrm{A}(1), \mathrm{A}(2)$, and $\mathrm{A}(3)$, respectively. The casing metal $\mathrm{A}(1)$ and the backliner $\mathrm{A}(3)$ is constituted of primary carbide $(\mathrm{CrFe}){ }_{7} \mathrm{C}_{3}$ (White, $H_{m v}=1300$ to 1850 ), fine secondary carbide $(\mathrm{CrFe}){ }_{23} \mathrm{C}_{6}$ and martensite $\left(H_{m v}=600\right.$ to 800$)$. And the metallic texture of impeller is constituted of pearlite $\left(H_{m v}=290\right.$ to 330$)$ and troostite $\left(H_{m v}=450\right.$ to 550$)$. Both hardness and metallic texture are agreed well.

Metal B is a $27 \mathrm{Cr}$ cast iron. Metal B(1) is the parent metal of frontliner used in the site I. The metallic texture is constituted of primary carbide $(\mathrm{CrFe})_{7} \mathrm{C}_{3}$, austenite $\left(H_{m v}=250\right.$ to 600$)$ and martensite. The hardness is almost the same as that of quenched casing due to the uniform distribution of carbide.

Metal $\mathrm{C}$ is a carbon steel which is constituted of ferrite $\left(H_{m v}=70\right.$ to 200$)$ and pearlite $\left(H_{m v}=250\right.$ to 320).

Metal D, E, F, G and $\mathrm{H}$ are hard surface coating materials. They were used in site II.

Metal $\mathrm{D}$ and $\mathrm{F}$ are self-fluxing nickel chromium hardfacing alloy powders which include silicon and boron as solvents. The surface coating layers formed on parent metal were treated again by fusing. The tight bonding metal between non-pore surface coating material and parent metal increased the impact and wear resistance. Here, the thickness of surface coating sprayed on reducer was 1.30 to $1.42 \mathrm{~mm}$ and its weight increment was about $14.0 \mathrm{~N}$.

Metal $\mathrm{E}$ and $\mathrm{G}$ are nickel base hardfacing alloy powder, and metal $\mathrm{H}$ is tungsten carbide composite. Those metals were sprayed on the frontliner by gas plasma spray apparatus. The thickness of surface

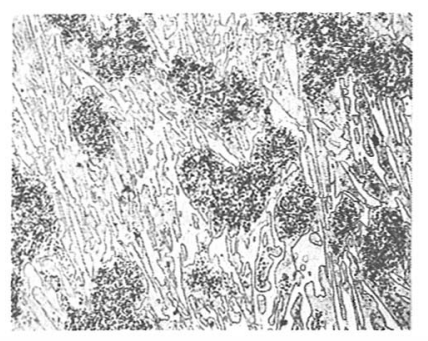

(a) Casing $\mathrm{A}(1)$

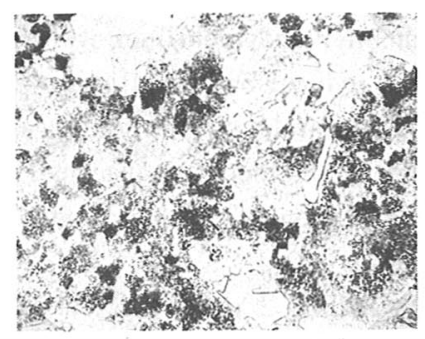

(b) Impeller $A(2)$

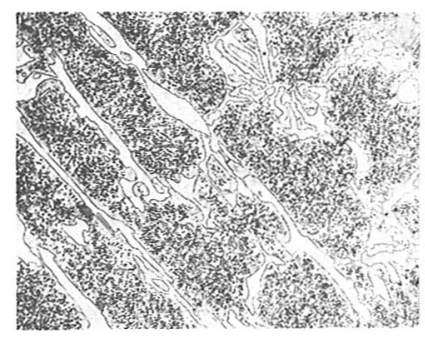

(c) Backliner A (3)

Photo. 2 Metallic texture $(\times 210)$. 
coating was about $0.42 \mathrm{~mm}$ and its weight was about $7.1 \mathrm{~N}$. On the impeller, metal $\mathrm{E}$ was sprayed. The thickness was about $0.42 \mathrm{~mm}$ and the weight was about $9.3 \mathrm{~N}$. Moreover, the wear tests were executed for casing sprayed by metal $\mathrm{H}$ and non-treated backliner.

In general, the relative wear resistance of surface coatings increases with increasing bulk hardness and strain hardening capacity of the matrix. The wear resistance of a tungsten carbide composite with a nickel alloy and carbide eutectic matrix is greater than that with a low alloy steel and carbide eutectic one $\mathrm{e}^{7}$. The tungsten carbide composites coatings treated with plasma spray are often exfoliated from parent metal by soil scratching due to the weak bonding strength. Therefore, the bonding strength between tungsten carbide composites $\mathrm{H}$ and smooth and hard surface of frontliner was increased by use of soft interlocking material $\mathrm{G}$.

\section{WEAR TESTS}

\section{(1) Method of measurement}

The amount of wear was measured as the weight difference before and after wear test. Here, a load cell of maximum capacity $980 \mathrm{~N}$ and sensitivity $0.12 \mathrm{~N}$ was used. And the shape variation of pump part due to wear was measured by use of a blocking gauge. This gauge was composed of a row of metal bars of $0.9 \mathrm{~mm}$ diameter and $85 \mathrm{~mm}$ length, of which width was $150 \mathrm{~mm}$. The measuring positions were on the 8 sections having an equivalent interval on the axis of reducer and frontliner, and the base line was set on each edge part of flange respectively.

(2) Wear of impeller

In site $I$, several wear tests were executed for the parent metals of impeller (2 blades, $440 \mathrm{~mm}$ diameter, $802 \mathrm{~N}$ initial weight) in $\mathrm{P}_{2}, \mathrm{P}_{4}$ and $\mathrm{P}_{e}$ pump respectively. Fig. 4 shows the relations between wear amount of impeller and ring number (dry weight of soil). During the wear test, the rotation speed of $P_{2}$ pump was measured to be 800 to 950 r. p. m., and the $P_{1}$ and $P_{e}$ were operated at 1185 r. p. m. . So, it is clarified that the wear amount of impeller in $\mathrm{P}_{4}$ or $\mathrm{P}_{e}$ is larger than that of impeller in $\mathrm{P}_{2}$. The shape variation of impeller due to wear was characterized by the inner concave blade scraped due to gouging wear action at the inlet of slurry and the outer thin blade abraded due to high speed impingement of soil particles.

\section{(3) Wear of reducer}

In site II, 6 kinds of wear tests were executed for the parent metals $A, C$ and the surface coatings D, F sprayed on metal $\mathrm{C}$ of reducers fixed to $\mathrm{P}_{2}$ or $\mathrm{P}_{\mathrm{e}}$ pump. Fig. 5 shows the relations between wear amount of reducer and ring number (dry weight of soil). It is clarified that the effect of surface coatings on wear resistance of reducer displays explicitly. That is, the wear of reducer treated with surface coatings progresses slowly at initial wear stage. Comparing the amount of wear of same metals each other, the wear

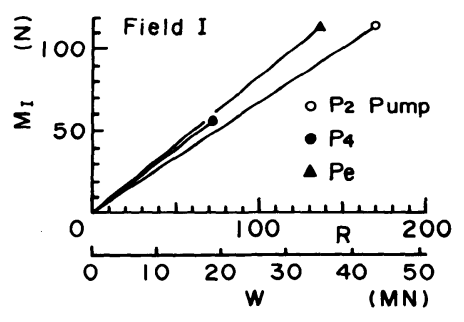

Fig. 4 Relations between wear amount of impeller $M_{1}$ and ring number $R$ (Dry weight of soil $\boldsymbol{W})$.

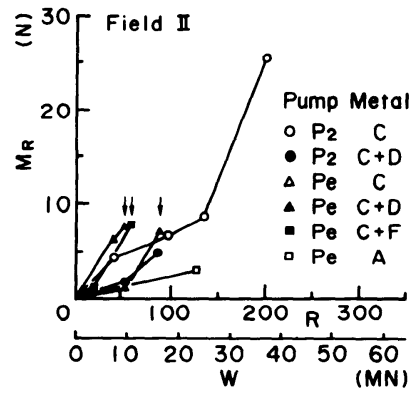

Fig. 5 Relations between wear amount of reducer $M_{k}$ and ring number $R$ (Weight of dry soil $W$ ). and arrow shows the failure point. 


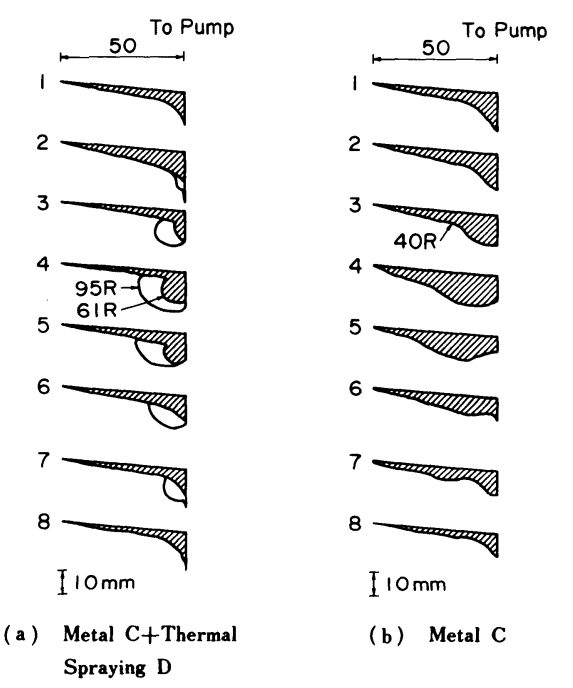

Fig. 6 Shape variation of reducer due to wear.

of reducer at $P_{e}$ pump progresses rapidly rather than that of reducer at $\mathrm{P}_{2}$ pump. Considering the hardness of slurry soil particles (feldspar $H_{m v}=$ 600 to 750 , quartz $H_{m v}=750$ to 1280 ) compared with that of metal texture, it is reasonable that the wear resistance of $20 \mathrm{Cr}$ cast iron shows many times as large as that of steel carbon. And the wear resistance of surface coating metal $\mathrm{D}$ shows approximately the same as that of $20 \mathrm{Cr}$ cast iron. At about 9. $8 \mathrm{MN}$ dry weight of soil, a part of surface coatings $\mathrm{D}$ was worn out and the parent metal was exposed. On the other hand, the surface coatings $\mathrm{F}$ was partially worn out at about $3.92 \mathrm{MN}$ dry weight of soil due to the comparatively low hardness. In this figure, arrows mean that the reducer becomes deeply pitted and is broken down. In this case, the reducer becomes useless at 2 to $3 \%$ weight loss as the weight of new one is about $294 \mathrm{~N}$.

Fig. 6 (a), (b) shows the shape variations of reducer due to wear at each measuring position in the case of surface coatings and carbon steel. In general, the surface coatings resist well for slurry erosion. It is characterised that the surface coating is exfoliated and the parent metal is worn out in a shape of decayed tooth at the junction to frontliner, especially at the bottom (positions 3 to 7 in Fig. 2). To prevent the progress of localized wear, it is necessary to exchange the setting position of reducer in every ten-odd rings. So, the wear life of reducer could be extended considerably. In the case of carbon steel without any surface coatings, the overall junction of reducer to frontliner is worn out and the amount of wear at the bottom is remarkably larger than the others. As a localized wear does not occur, the wear life of reducer is fairly long as shown in metal $\mathrm{C}$ at $\mathrm{P}_{2}$ pump in Fig. 5 .

\section{(4) Wear of frontliner}

In site $I, 4$ kinds of wear tests were executed for the parent metals $A$ and $B$ of front-liner in $P_{2}, P_{1}$ and $P_{e}$ pumps. And in site II , 5 kinds of wear tests were executed for the parent metal $A$ and surface coatings $E$ and $G+H$ sprayed on metal $A$ of frontliner in $P_{2}$ and $P_{e}$ pumps respectively. Fig. 7(a), (b) show the relations between wear amount of frontliner and ring number (dry weight of soil) at sites $I$ and II. At site I, the mutual relations between amounts of wear and metal properties are not clarified, but the wear life of frontliner in $\mathrm{P}_{2}$ pump is the longest in all of them. Arrows in this figure show the position that the frontliner becomes useless due to making a hole. In this case, the wear life of frontliner corresponds to 
about $40 \%$ weight loss as the weight of new one is $502.7 \mathrm{~N}$. At site II, neither the influences of pump on the amount of wear of frontliner nor the effect of surface coatings on it are clarified in this test. The latter cause is that the surface coating used here is not a thick one sprayed by self-fluxing alloy powder but is remarkably thin one to be $0.42 \mathrm{~mm}$. If a self-fluxing powder is used, it is necessary to perform preheating the parent metal and then fusing the surface coatings. As a result, the hardness of $20 \mathrm{Cr}$ cast iron decreases and also the wear resistance drops down remarkably. The average wear rates of frontliner (wear amount/dry weighht of soil) at site I and II are calculated to be 2.54 and $2.64 \mathrm{~N} / \mathrm{MN}$ respectively. The difference between them is caused by the average grain size of slurry soil.

Fig. 8(a), (b) show the shape variations of frontliner due to wear in $P_{2}$ and $P_{4}$ pump at each measuring position. The overall sliding parts to impeller (440 $\mathrm{mm}$ outer diameter and $200 \mathrm{~mm}$ inner one) were uniformly worn at the initial small ring numbers. On the progress of wear, the wear surface varied to an uneven complicate concentric phase. In $\mathrm{P}_{4}$ pump, the frontliner was made a hole at the inside of inlet and was worn out at 318 rings. As in the case of reducer, the frontliner was worn remarkably at the bottom of inlet side (position 4 and 5). And the center of sliding parts to impeller was worn out eccentrically. Usually, the clearance between frontliner and impeller was controlled to be about $1 \mathrm{~mm}$. The large grain-size soil particles inserted in the space provoked an abrasive wear between them. Furthermore, the inlet parts of frontliner were worn out remarkably

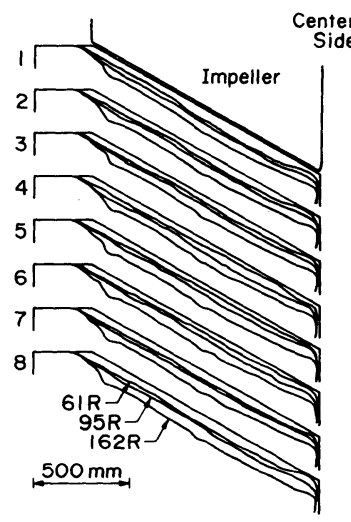

(a) Pump $\mathrm{P}_{2}$ Metal $\mathrm{A}$

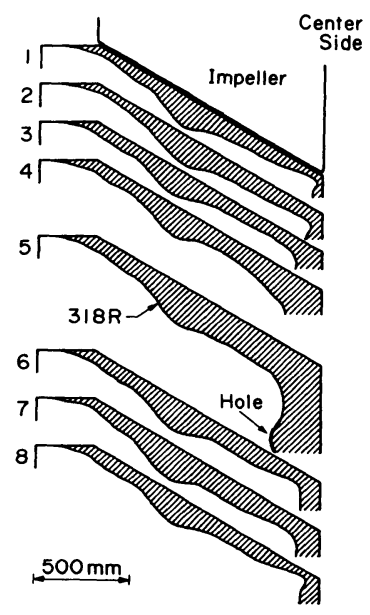

(b) Pump P4, Metal B

Fig. 8 Shape variation of frontliner due to wear (Field II). to the rotation of impeller. To increase the durability of front liner, it is necessary to exchange the setting position periodically.

\section{CONSIDERATIONS}

The above mentioned slurry pump is a centrifugal volute pump. That is, the slurry is applied energy of motion by a rotating impeller and flows into the radial direction at the inlet of impeller which is right to the inflow axis of frontliner. After the slurry has flowed spirally in the frontliner and has been accelerated by the impeller blades, the velocity decreases in the casing and then the kinetic energy is converted into a pressure energy. To study the wear characteristics of pump parts, it is necessary to analyse the hydrodynamic mechanism of slurry in a pump as a solid-liquid two-phase flow and to clarify the dynamic frictional phenomena between metal and soil particles.

Wilson ${ }^{8)}$ reported the wear phenomena due to slurry being pumped and the materials used to resist abrasive wear, and he discussed about the hydraulic design of impeller and casing and their relationship to wear and hydraulic unbalance. The angle of the particle contact on the pump parts and their velocity at impeller vane inlet and casing cutwater are directly influenced by the system head point on the pump characteristic curve. These condition points can be classified into BEP zone, overcapacity zone, partial capacity zone and shut valve zone. It is recommended that a pump should be selected to operate at partial capacity close to the BEP zone where the angles of the slurry flow coincide with that of the pump.

In a reducer, erosion or low stress abrasion arises from the impingement of freely moving particles at higher velocity or of moving particles parallel to the wearing surface at low velocity. The limit deposit 
velocities of the slurry in the reducers of sites I and II at the inlet of pump are calculated to be 3.83 and $3.61 \mathrm{~m} / \mathrm{s}$ respectively. These values are greater than the designed flow velocities in the straight pipes. In a reducer, the slurry is transfered from the state of suspended flow to the one of bed-load movement. Therefore, it is considered that the amount of wear of reducer at the bottom position near the pump inlet increases remarkably.

Although a secondary flow pattern measured in the unshrouded impeller passage appears to be very strongly influenced by the flow entering the passage through the clearance between blade tip and frontliner ${ }^{9)}$, the impact energy of soil particles in an impeller increases at least radially and the thickness of blade decreases in the radial direction. Closed impeller designs are preferred to open impellers since the passages between the inlet and the outlet are usually relatively evenly worn.

Abrasive particles entered into the clearance between rubbing surface of impeller and frontliner with sufficient force produce a crushing action on the mineral particles, and high stress and grinding abrasion are imposed causing micro-spalling or fracturing of brittle constituents in the wearing material. Deterioration occurs on a frontliner from abrasive scratching and local plastic flow. As the abrasive wear is scarcely influenced by velocity the shape variation of frontliner at the rubbing parts to blade tips progresses uniformly. As the clearance between them increases on the progress of wear, an eccentric wear zone tends to develop due to concentration of soil particles to some place.

Elkholy ${ }^{10)}$ reported that the wear amount of slurry pump materials $\mathrm{W}$ can be expressed for any sample of cast iron by the velocity of particles $V$, the impingement angle $\alpha$, the ratio $H_{1} / H_{2}$ of the solid particle hardness $H_{1}$ to the eroded material hardness $H_{2}$, the solid particle size $d$, the slurry concentration $C_{v}$ by volume, time $T$, and constants $K, n$ as follows:

$$
W=K C_{v}^{0.682}\left(H_{1} / H_{2}\right)^{n} d^{0.616} V^{2.39} \times\left\{1+\sin \left(2 \alpha-90^{\circ}\right)\right\} T
$$

As the flow mechanism in a pump is very complicated, the estimation of wear amount of pump part by means of determining accurately the above mentioned factors is fairly difficult.

On the wearing surface of metal, gouging abrasion occurs when coarse materials impinge with sufficient force that high impact stresses are imposed at some angle of impingement ${ }^{111}$. In general, cutting and plastic deformation wear are occurred by horizontal and normal component of kinetic energy of soil particles, respectively. Assuming that for cutting wear $\phi$ unit of kinetic energy must be absorbed by the surface to release one unit mass of eroded material and that the corresponding parameter for plastic deformation wear is $\varepsilon$, the following relationship is introduced ${ }^{12)}$.

$$
\begin{aligned}
& M=Q\left(V^{2} \cos ^{2} \alpha-v_{\rho}^{2}\right) / 2 \phi+Q\left(V \sin \alpha-V_{n}\right)^{2} / 2 \varepsilon \text { for } \alpha<\alpha_{0} \\
& M=Q V^{2} \cos ^{2} \alpha / 2 \phi+Q\left(V \sin \alpha-V_{n}\right)^{2} / 2 \varepsilon \text { for } \alpha>\alpha_{0}
\end{aligned}
$$

in which $M$ is the erosion produced by $Q$ tons of particles at angle of impingement $\alpha$ and particle velocity $V$. $V_{n}$ is the velocity component normal to the surface below which no erosion takes place in certain hard materials and $v_{p}$ is the residual parallel component of particle velocity at small angle of impingement. $\alpha_{0}$ is the angle of impingement at which $v_{p}$ is zero.

In the case of estimating wear amount of casing, it is fairly difficult to determine the above mentioned factors $Q, V, V_{n}, v_{p}, \alpha, \phi$ and $\varepsilon$ on the curved surface.

Table 3 shows the average wear amount (weight of wear per unit dry weight of soil) and the average wear life (transported dry weight of soil until breakdown) of pump parts in the wear tests. It is evident that the frontliner, impeller and reducer $(A, C+D, C)$ are arranged in order of wear life rank. On the other hand, the impeller, frontliner and reducer $(C$, $C+D, A)$ are arranged in order of wear rate rank. The wear rate of impeller is larger than that of frontliner owing to the low surface hardness and the large wearing surface.

Table 3 Wear amount and wear life of pump parts.

\begin{tabular}{|c|c|c|c|c|c|}
\hline \multicolumn{2}{|c|}{} & \multicolumn{2}{|c|}{ Wear amount (N/MN) } & \multicolumn{2}{c|}{ Wear life (MN) } \\
\hline \multicolumn{2}{|c|}{ Site } & I & II & I & II \\
\hline \multicolumn{2}{|c|}{ Impeller } & 3.01 & - & 55.4 & - \\
\hline \multirow{3}{*}{ Reducer er } & C+D & - & 0.35 & - & 15.7 \\
\cline { 2 - 6 } & C & - & 0.73 & - & 9.5 \\
\cline { 2 - 6 } & A & - & 0.11 & & 26.8 \\
\hline \multicolumn{2}{|r|}{ Frontliner } & 2.54 & 2.64 & 85.7 & 87.1 \\
\hline
\end{tabular}




\section{CONCLUSIONS}

Wear tests for slurry pump parts at 2 shield tunneling sites were executed. The test results and the counterplan against wear to be considered are as follows :

(1) The effects of surface coatings treated on a reducer are displayed remarkably at initial stage of wear. To exhibit fully the effect of thermal spraying, it is necessary to rotate the setting position of reducer periodically. Although the wear resistance of $20 \mathrm{Cr}$ cast iron used for a parent metal of reducer is excellent, the selection of $20 \mathrm{Cr}$ cast iron or surface coatings should be considered from economical standpoint.

(2) The overall junction of reducer to frontliner is worn out. The amount of wear at the bottom is remarkably large. As the surface coatings resist well for slurry erosion, the parent metal is worn out in a shape of decayed tooth after exfoliation of the surface coatings.

(3) To prevent the eccentric wear at bottom of reducer or frontliner, it is necessary to increase the flow velocity at the inlet of pump not to occur a state of bed-load slurry movement.

(4) The overall sliding parts of frontliner to blade tips of impeller are uniformly worn at the initial wear stage. On the progress of wear, the wear surface varies to an uneven complicate concentric phase especially at the bottom of inlet side and the center of sliding parts is worn out eccentrically. The amount of wear of frontliner increases with the increment of average grain-size of slurry.

(5) For both frontliner and impeller, the effect of surface coatings does not appear remarkably in this test.

(6) The frontliner, impeller and reducer are arranged in order of wear life rank. It is possible to build up a rational counterplan against wear and an useful project for exchange of pump parts.

The authors would like to express their sincere thanks to Prof. S. Hata, Kyoto University and the members of committee of wear counterplan, Kansai Branch, J.C.M. A. to execute wear test.

\section{REFERENCES}

1) Murakami, S., Kawashima, T., Tsukahara, S. and Okada, T. : Wear test of pipe linings for hydraulic transport of dam deposit, Hydrotransport 7, H2, pp.315 330, 1980.

2) Okayama, Y., Murakami, Y. and Hamada, K. : Studies on the wear of slurry pipelines, Report of the port and harbour research institute, Vol.20, No.2, pp. 271 311, 1981.

3) Takeishi, T. : State-of-the-art report on wear of dredger, Constrution Machinery and Equipment, Vol. 12, No. 7, pp. 75 82, 1976.

4) Yoshikawa, T., Uto, Y. and Nunomura, S. : A study of shield tunnelling machine, Hitach Zosen Technical Report, Vol. 42 , No. 1 , pp. $51 \sim 58,1981$.

5) Durand, A. : Basic relationships of the transportation of solids in pipes, Proc. Minnesota International Hydraulics, Convention, I. A. H. R. , pp. 89 103, 1953.

6) Ogawa, H. : Wear amount of drainage slurry pipe, Journal of the JSCE, Vol.55, No. 12, pp. 59 62, 1970.

7) Moore, M. A. : The abrasive wear resistance of surface coatings, J. agric. Engng. Res. 20, pp. 167 179, 1975.

8) Wilson, G. : The design aspects of centrifugal pumps for abrasive slurries, Proc. of the 2nd Int. Conf. on the Hydraulic Transport of Solids in Pipes, H 2, pp. 25 52, 1972.

9) Howard, J.H.G. and Kittmer, C.W. : Measured passage velocities in a radial impeller with shrouded and unshrouded configuration, J. of Engineering for Power, pp. 207 213, 1975.

10) Elkholy, A. : Prediction of abrasive wear for slurry pump materials, Wear, 84, pp. 39 49, 1983.

11) Muro, T. : Wear characteristics of metal due to soil and rock, Construction Machinery and Equipment, Vol. 19, No. 4, pp. 36 41, 1983.

12) Neilson, J.H. and Gilchrist, A. : Erosion by a stream of solid particles, Wear, 11, pp. 111 122, 1968. 